\title{
A Novel Educational Control Group Mobile App for Meditation Interventions: Single-Group Feasibility Trial
}

Jennifer Huberty ${ }^{1}$, PhD; Ryan Eckert ${ }^{2}$, MSc; Megan Puzia ${ }^{3}$, MSc; Breanne Laird ${ }^{1}$, BSc; Linda Larkey ${ }^{4}$, PhD; Ruben $\mathrm{Mesa}^{2}, \mathrm{MD}$

${ }^{1}$ College of Health Solutions, Arizona State University, Phoenix, AZ, United States

${ }^{2}$ Mays Cancer Center, University of Texas Health San Antonio MD Anderson, San Antonio, TX, United States

${ }^{3}$ Behavioral Research and Analytics, LLC, Salt Lake City, UT, United States

${ }^{4}$ Edson College of Nursing and Health Innovation, Arizona State University, Phoenix, AZ, United States

Corresponding Author:

Jennifer Huberty, $\mathrm{PhD}$

College of Health Solutions

Arizona State University

500 North 3rd Street

Phoenix, AZ, 85004

United States

Phone: 14023011304

Email: jhuberty@asu.edu

\section{Abstract}

Background: Smartphone ownership is becoming ubiquitous among US adults, making the delivery of health interventions via a mobile app (ie, mobile health [mHealth]) attractive to many researchers and clinicians. Meditation interventions have become popular and have been delivered to study participants via mobile apps to improve a range of health outcomes in both healthy adults and those with chronic diseases. However, these meditation mHealth interventions have been limited by a lack of high-quality control groups. More specifically, these studies have lacked consistency in their use of active, time-matched, and attention-matched control groups.

Objective: The purpose of this study is to beta test a novel health education podcast control condition delivered via a smartphone app that would be a strong comparator to be used in future studies of app-based meditation interventions.

Methods: Patients with myeloproliferative neoplasm (MPN) cancer were recruited nationally. Upon enrollment, participants were informed to download the investigator-developed health education podcast app onto their mobile phone and listen to $\sim 60$ $\mathrm{min} /$ week of cancer-related educational podcasts for 12 weeks. The benchmarks for feasibility included $\geq 70 \%$ of participants completing $\geq 70 \%$ of the prescribed $60 \mathrm{~min} /$ week of podcasts, $\geq 70 \%$ of participants reporting that they were satisfied with the intervention, and $\geq 70 \%$ of participants reporting that they enjoyed the health education podcasts.

Results: A total of 96 patients with MPN were enrolled in the study; however, 19 never began the intervention. Of the 77 patients who participated in the intervention, 39 completed the entire study (ie, sustained participation through the follow-up period). Participation averaged 103.2 (SD 29.5) min/week. For 83.3\% (10/12) of the weeks, at least 70\% of participants completed at least $70 \%$ of their total prescribed use. Almost half of participants reported that they enjoyed the health education podcasts (19/39, $48.7 \%)$ and were satisfied with the intervention $(17 / 39,43.6 \%)$. There were no significant changes in cancer-related outcomes from baseline to postintervention.

Conclusions: A 12-week, health education podcast mobile app was demanded but not accepted in a sample of patients with cancer. Using the mobile app was not associated with significant changes in cancer-related symptoms. Based on findings from this study, a health education podcast mobile app may be a feasible option as a time- and attention-matched control group for efficacy trials with more extensive formative research for the content of the podcasts and its acceptability by the specific population.

Trial Registration: ClinicalTrials.gov NCT03907774; https://clinicaltrials.gov/ct2/show/NCT03907774

(JMIR Form Res 2020;4(7):e19364) doi: 10.2196/19364 


\section{KEYWORDS}

feasibility; smartphone; mHealth; digital health; cancer; beta test

\section{Introduction}

Smartphone ownership is becoming ubiquitous among adults in the United States (81\% in 2019) [1]. Using mobile devices to support health and wellness (ie, mobile health [mHealth]) [2] may be a promising approach to help individuals prevent or manage chronic conditions and improve health outcomes [3]. However, many studies of mHealth interventions, particularly mobile app interventions, have been substantially limited by the lack of high-quality comparators (ie, control conditions). The most common types of control conditions include usual care (ie, usual care for the critical condition), wait-list control (ie, usual care and will later receive the intervention), and active control (ie, control group receives an activity or intervention that controls for some aspect of attention, time, or expectation) [4]. Active control groups can be more effective than wait-list control groups [5]. However, there is a lack of research on active control groups in app-based interventions [6,7]. Recent reviews and meta-analyses have called for improvements in the design of control groups within randomized control trials that evaluate the efficacy of mobile app interventions [4,8], and the National Institutes of Health (NIH) has recommended that careful selection of a comparator be designed to reflect the primary purpose of the study [9]. It is clear that there is a need for active time- and attention-matched comparators. That is, control conditions must aim to not only match the mode of activity or delivery of the intervention but also match the time and attention that is spent on the intervention. Without active control conditions that match interventions with regard to time and attention, studies of mHealth interventions are unavoidably confounded by differences in participant engagement [9]. There is a need to design and explore the feasibility of active timeand attention-matched control groups for mHealth studies.

Meditation apps have become quite popular in recent years $[4,10]$ and have been used to improve mental and physical health in a range of healthy [7,11-15] and health-compromised populations [16,17]. However, few mobile app meditation studies have used active, time-matched, and attention-matched comparators $[7,13,14,18]$ even when the study primarily aimed to determine effectiveness or efficacy. The most common comparators for these studies have been wait-list control groups, usual care, and educational handouts [12,15]. For example, in our work using a meditation app to reduce symptom burden in patients with hematological cancer, we used an educational handout with information about managing fatigue in cancer as our control group. Participation in the control group was not associated with improvements in health or cancer-related symptoms, suggesting that the cancer-related educational content may be reasonable for a control condition; however, this group did not match the engagement level of our intervention participants. This type of comparator could be improved by modifying it to mirror the basic functionality, look, and feel of the intervention group's meditation app (ie, active); match the time that the intervention group spends participating in meditation (ie, time-matched); and match the attention and basic mode of delivery that the intervention group requires to meditate (ie, attention-matched).

We sought to develop and beta-test an appropriate comparator app for interventions using a mobile meditation app. We developed the app with the ability for content to be modified, added, and updated, and be used across various populations participating in mobile meditation interventions. To further our progressive line of research, we chose to conduct the beta test in patients with hematological cancer (specifically, myeloproliferative neoplasm [MPN]) due to our ongoing work with this population and our partnerships with foundations in which to recruit patients with cancer for our beta test. Therefore, the purpose of this study is to beta test a novel health education podcast control condition delivered via a mobile app that would be a strong comparator to be used in future studies of app-based meditation interventions. We hypothesized that implementing the health education podcasts in a sample of patients with MPN would be feasible (ie, demanded, accepted) and that using the podcasts would not be associated with significant improvements in health, cancer-related symptoms (ie, depression, anxiety, pain intensity, and sleep disturbance), or total symptom burden. Our benchmarks for success were $\geq 70 \%$ of participants completing $\geq 70 \%$ of the prescribed $60 \mathrm{~min} /$ week of podcasts, $\geq 70 \%$ satisfied with the intervention, and $\geq 70 \%$ enjoying the health education podcasts.

\section{Methods}

This study was approved by the Institutional Review Board at Arizona State University.

\section{Recruitment and Enrollment}

Guided by Bowen and colleagues' [19] recommendations for designing feasibility studies, we aimed to enroll 100 participants in the study [19]. Because these early trials are used, in part, to estimate effect size and power for future trials, we did not expect to be fully powered to detect changes in primary study outcomes. Participants were recruited nationally via internet-based strategies, including social media (ie, Facebook, Twitter), social networking sites, and online and email listservs. All recruitment methods were approved by the Arizona State University Institutional Review Board. The study was advertised as a mobile app health education intervention. We recruited self-reported patients with hematological cancer (ie, patients with MPN) because we have a progressive line of work involving patients with MPN using mindfulness approaches to reduce symptom burden (eg, yoga, meditation). However, the app was developed to be applied in app-based meditation interventions across various populations. Interested participants completed an eligibility link on REDCap (Vanderbilt University). Inclusion criteria were as follows: (1) had a diagnosis of MPN (ie, polycythemia vera, myelofibrosis, essential thrombocythemia) identified by a treating physician, (2) had access to a smartphone on a regular basis, (3) had access to reliable home internet, (4) could read and understand English, and (5) were 18 years or older. The exclusion criteria were as 
follows: (1) planned change in pharmacologic intervention (ie, new drug, bone marrow transplant) during the study interval (ie, 12 weeks) and (2) resided outside of the United States. If eligible, the patients were emailed a link to a video explaining the informed consent and study procedures. If interested, patients were asked to respond to the email indicating that they reviewed the video and had the opportunity to ask questions. Patients then completed an electronic informed consent delivered via REDCap prior to participation. If ineligible, patients were sent an email notification thanking them for their interest in the study and to respond if they were interested in being notified about future studies.

\section{Research Design}

The study was a single-group, beta test study of a new control intervention to be used as a comparator in future studies involving mindfulness and meditation mobile apps. A total 96 participants were enrolled in the study and assigned to a health education podcast group.

\section{Podcast Control App Development}

The concept for the podcast control app was developed by a $\mathrm{PhD}$-level mHealth researcher with expertise in the development of national, digitally delivered interventions to improve physical and mental health. The goal was to develop an app that could deliver education information in the same context that a consumer-based mindfulness meditation app delivers content (ie, log onto an app, click on the content, listen). See Figure 1 for a screenshot of the Mindful Health Lab (MHL) podcast control app. The podcast control app was developed to match time (ie, 60-70 min/week) and attention (ie, same context of delivery and same functionality) of some mobile app meditation interventions $[6,7,15]$. We used the mobile app Calm as our model because of our long-standing partnership and research being conducted with the app $[15,16]$. The app was also developed so that content could be changed and tailored to any population in future studies. For example, if the study team was conducting a study in college students with the Calm app, the podcast health education content could be modified to be specific to college students. In the case of this study, we used patients with cancer. Thus, content was tailored to health education for patients with cancer. The app was designed to have the same general features as the Calm app (eg, reminders to listen to podcasts, ability to share use on social media, ability to track time spent listening to podcasts) but without the same branding. We did not include similar branding as Calm to keep control participants blinded to the app that would be used in the intervention group.

Figure 1. Mindful Health Lab (MHL) podcast app screenshot.

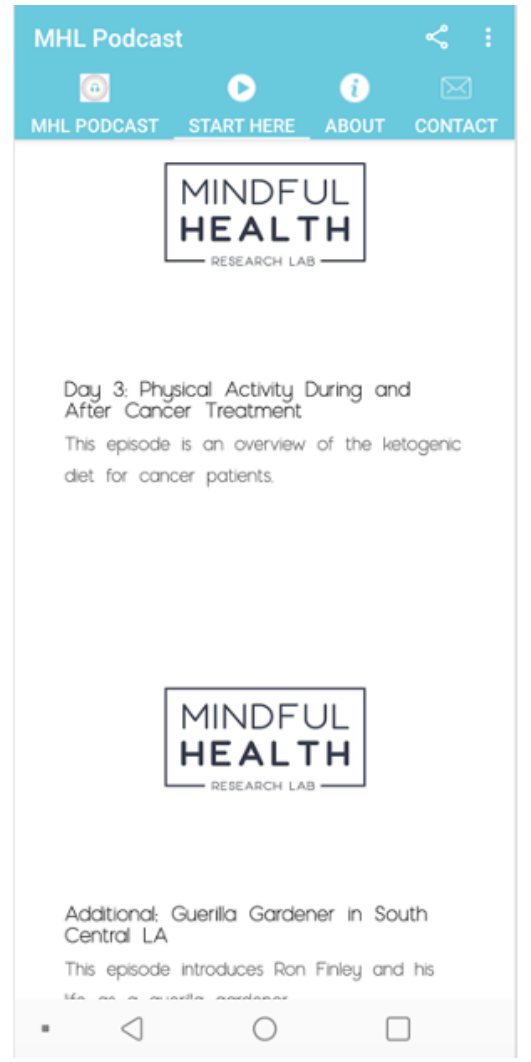

To gather content for the app, the research team searched publicly available podcasts related to health education through credible government and higher education websites and podcasts that could be used with our target population for our beta test (ie, patients with cancer). The selected content was then uploaded to an app created by a developer. The podcast content was only used for noncommercial purposes with credit to the source of the content included in the app. The audio was not changed or altered in any way and only those enrolled in the study had access to the content. The type of specific educational content included a variety of topic areas including nutrition, physical activity, time, and stress management, as well as general wellness and life-related topics (eg, cultivating happiness, organization practices). 


\section{Podcast Control App Prescription}

Participants were asked to listen to the health education podcasts on their smartphone for approximately $60 \mathrm{~min} /$ week for 12 weeks. Podcasts were arranged by week and by day. There were approximately two to three podcasts prescribed per week, averaging about 22 minutes per podcast. Additionally, there were one to three podcasts offered per week for participants to complete if they wanted to listen to more than $60 \mathrm{~min} /$ week. Although navigation through the podcast prescription was suggested by week, participants were not restricted from skipping around within the weeks. Time spent listening to the podcasts was collected by the app and downloaded by the research team.

\section{Outcomes}

The a priori benchmarks for feasibility were based on Bowen and colleagues [20] feasibility criteria and included $\geq 70 \%$ of participants completing $\geq 70 \%$ of the prescribed $60 \mathrm{~min} /$ week (42 min/week) of podcasts (ie, demand), $\geq 70 \%$ of participants reporting that they were satisfied with the intervention, and $\geq 70 \%$ of participants reporting that they enjoyed the health education podcasts (ie, acceptability). These specific benchmarks have been used successfully in other recent feasibility studies [16,21].

Questionnaires were administered at baseline (week 0), midintervention (week 6), and postintervention (week 12). These questionnaires included demographics (baseline only), satisfaction-related questions developed by the researchers (week 12 only), NIH Patient-Reported Outcomes Measurement Information System (PROMIS) outcomes (global health, pain intensity, anxiety, depression, and sleep disturbance), and the MPN Symptom Assessment Form Total Symptom Score (MPN-SAF TSS). The satisfaction questionnaire asked questions related to enjoyment, satisfaction, recommendation to others, etc (see Textbox 1 for satisfaction survey questions and responses). Answers were either a yes or no format, or a 5-point Likert scale. The NIH PROMIS is a valid and reliable tool for the measurement of symptoms among patients with cancer [22-25]. The MPN-SAF TSS is a valid and reliable way of assessing total symptom burden among patients with MPN [5]. All participants were provided with a US \$25 digital gift card for completion of all questionnaires.

Textbox 1. Postintervention satisfaction survey questions.

1. On a scale of 1 to 5 (1=did not enjoy at all, $5=$ very much enjoyed), how would you rate your overall enjoyment of listening to the podcasts?

2. On a scale of 1 to 5 (1=not at all satisfied, $5=$ very much satisfied), how would you rate your overall satisfaction with the podcasts?

3. Would you recommend that other patients with myeloproliferative neoplasm (MPN) listen to the 12-week podcast prescription? Yes

No

4. Do you feel like you learned something about your MPN, or about cancer in general, that you did not know before starting the study? Yes

No

5. Have you made any changes to your normal daily activities because of something that you learned in the podcast? Yes No

6. Did you experience any limitations while trying to access the podcasts?

No, none

Bad or slow internet connection

Hard to hear or view the podcasts

Smartphone broken

Other, please describe: [free response textbox]

7. Do you have anything else you would like to share with us in regard to your participation in the MPN podcast study?

[Free response textbox]

\section{Statistical Analysis}

All analyses were conducted using SPSS 26.0 (IBM Corp). Descriptive statistics were used to characterize participants' app-use patterns over time, and frequency data from the satisfaction survey were used to describe participants' perceptions of the podcasts and the prescription schedule. Changes in PROMIS outcomes and MPN-SAF TSS were assessed using multivariate analyses of variance.

\section{Results}

\section{Recruitment and Enrollment}

Initially, 96 patients with MPN were enrolled in the study; however, 19 (19.8\%) never began the intervention without disclosing their reasoning and without responding to contact attempts (see Figure 2). Of the 80 patients who participated in the intervention, 39 (48.8\%) completed the entire study (ie, 
sustained participation through the follow-up period). There were 28 participants lost to follow-up that never responded to the three contact attempts after initial enrollment and 16 that dropped out and provided the research team with a specific reason for discontinuing the study. The reasons for dropout included content not being MPN-specific $(n=10)$, lack of time $(n=3)$, internet connectivity issues $(n=1)$, or illness or hospitalization $(n=2)$.

Enrollment by week is presented in Figure 3. Analyses included data from all participants who were enrolled in the study through the point that they stopped using the app, defined as the point at which participants did not engage with the app for any subsequent weeks during the intervention period. For example, if a participant used the app during weeks $1,2,3$, and 8, they were included in adherence analyses for weeks 1-8 (with use during weeks 4-7 calculated as 0 minutes) but were not included in analyses after the point when they stopped using the app (weeks 9-12), at which point they were considered to have discontinued study participation.

As shown in Table 1, the sample was predominately White, non-Hispanic, and female. The average age was 56.1 (SD 10.9) years. Most participants had earned a higher education degree, were married, and had an annual household income more than US $\$ 61,000$. Study noncompleters were demographically similar to those who completed the study.

Figure 2. Study consort diagram. MPN: myeloproliferative neoplasm.

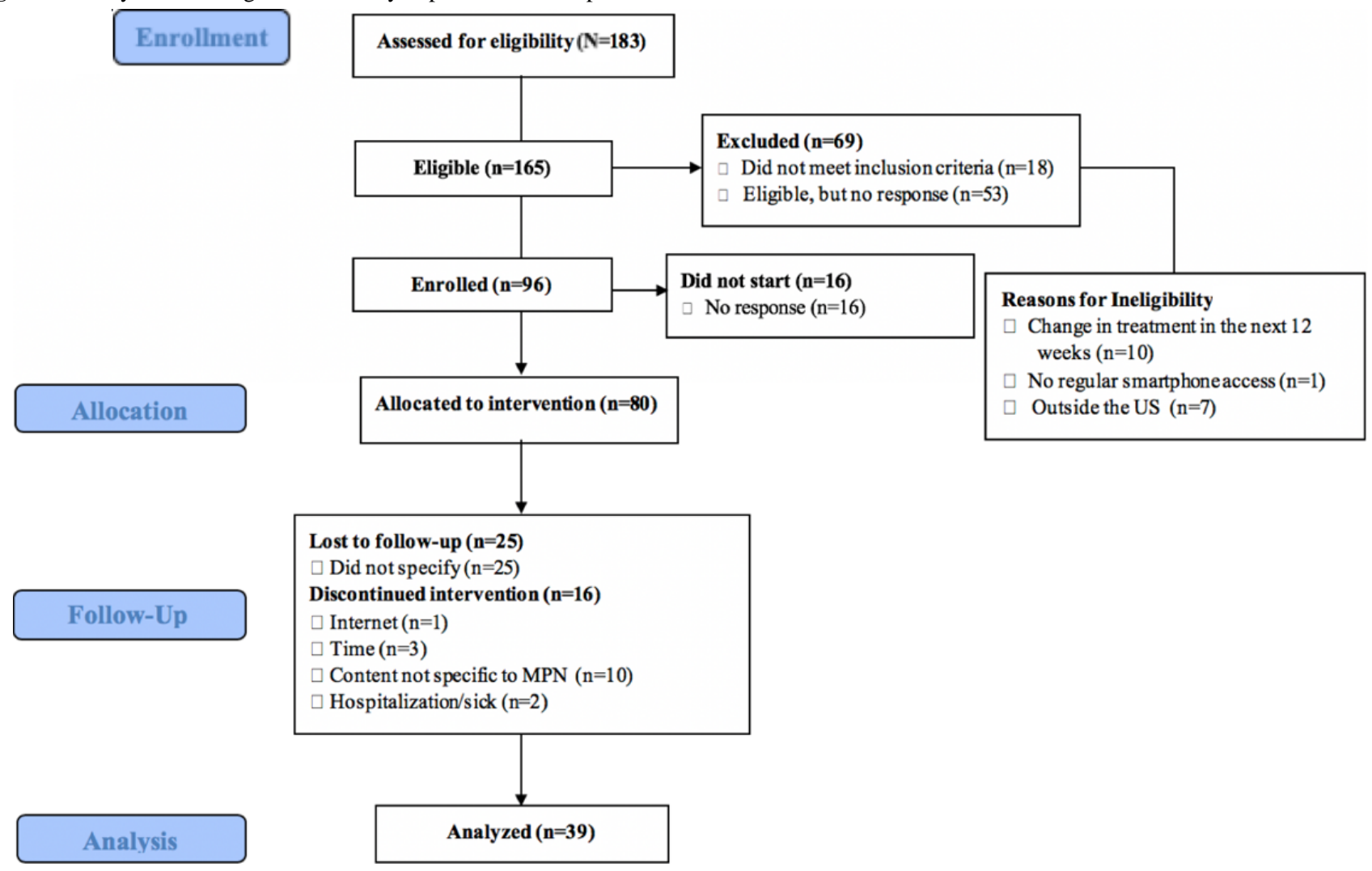

Figure 3. Participation and attrition by week during the intervention period.

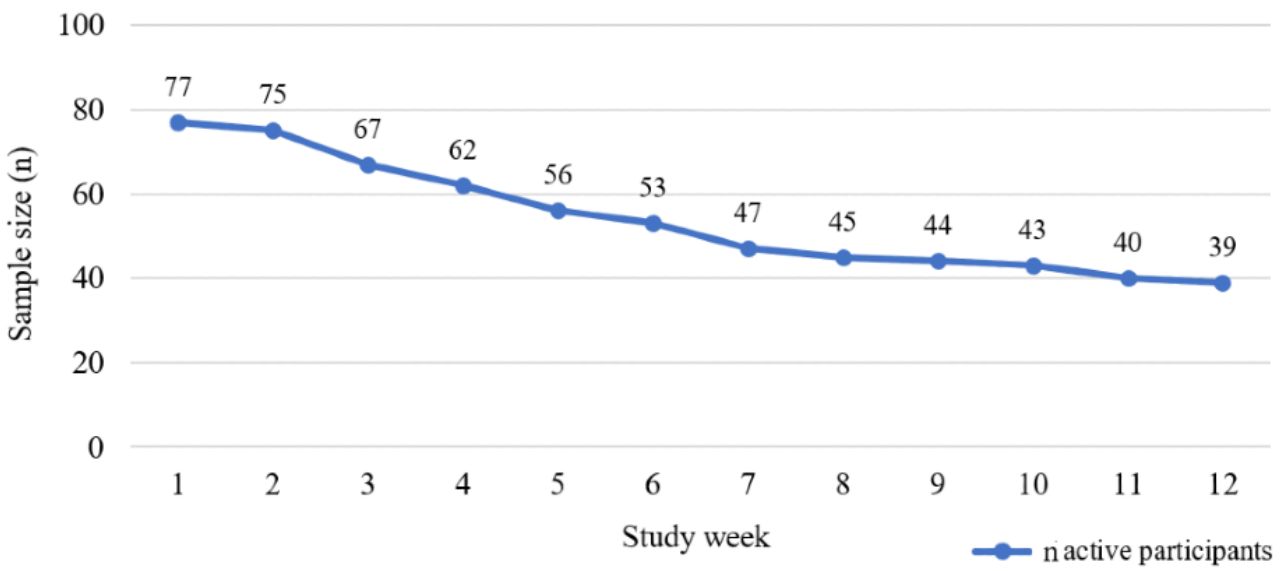


Table 1. Demographic characteristics of the sample.

\begin{tabular}{|c|c|c|}
\hline Category & Completed study $(\mathrm{n}=39), \mathrm{n}(\%)$ & Did not complete study $(\mathrm{n}=38), \mathrm{n}(\%)$ \\
\hline \multicolumn{3}{|l|}{ Gender } \\
\hline Female & 37 (94.9) & $33(86.8)$ \\
\hline Male & $2(5.1)$ & $5(13.2)$ \\
\hline \multicolumn{3}{|l|}{ Race } \\
\hline White & $38(97.4)$ & $35(92.1)$ \\
\hline Black/African American & $0(0.0)$ & $1(2.6)$ \\
\hline Asian & $1(2.6)$ & $1(2.6)$ \\
\hline American Indian & $0(0.0)$ & $2(5.3)$ \\
\hline Other & $1(2.6)$ & $1(2.6)$ \\
\hline \multicolumn{3}{|l|}{ Ethnicity $^{\mathrm{a}}$} \\
\hline Non-Hispanic & $38(97.4)$ & $37(100.0)$ \\
\hline Hispanic & $1(2.6)$ & $0(0.0)$ \\
\hline \multicolumn{3}{|l|}{ Education } \\
\hline High school/GED ${ }^{\mathrm{b}}$ & $2(5.1)$ & $2(5.3)$ \\
\hline Some college & $3(7.7)$ & $10(26.3)$ \\
\hline Associate's degree & $1(2.6)$ & $5(13.5)$ \\
\hline Bachelor's degree & $17(43.6)$ & $9(23.7)$ \\
\hline Graduate's degree & $16(41.0)$ & $12(31.6)$ \\
\hline \multicolumn{3}{|l|}{ Marital status } \\
\hline Single & $2(5.1)$ & $3(7.9)$ \\
\hline Partnered & $1(2.6)$ & $2(5.3)$ \\
\hline Married & $33(84.6)$ & $28(73.7)$ \\
\hline Divorced & $3(7.7)$ & $3(7.9)$ \\
\hline Widowed & $0(0.0)$ & $2(5.3)$ \\
\hline \multicolumn{3}{|l|}{ Income (US \$) ${ }^{\mathbf{a}}$} \\
\hline$<20,000$ & $3(7.7)$ & $5(13.5)$ \\
\hline $21,000-40,000$ & $3(7.7)$ & $5(13.5)$ \\
\hline $41,000-60,000$ & $5(12.8)$ & $7(18.9)$ \\
\hline$>61,000$ & $28(71.8)$ & $20(54.1)$ \\
\hline \multicolumn{3}{|l|}{ Chronic conditions } \\
\hline Anxiety & $10(25.6)$ & $12(31.6)$ \\
\hline Hypertension & $8(20.5)$ & $8(21.1)$ \\
\hline Arthritis/rheumatic disease & $7(17.9)$ & $5(13.2)$ \\
\hline Depression & $6(15.4)$ & $8(21.1)$ \\
\hline Asthma & $3(7.7)$ & $3(7.9)$ \\
\hline Hypercholesterolemia & $3(7.7)$ & $4(10.5)$ \\
\hline PTSD $^{c}$ & $2(5.1)$ & $1(2.6)$ \\
\hline Diabetes & $1(2.6)$ & $3(7.9)$ \\
\hline Heart disease & $1(2.6)$ & $0(0.0)$ \\
\hline Other & $9(23.1)$ & $4(10.5)$ \\
\hline None & $1(2.6)$ & $8(21.1)$ \\
\hline
\end{tabular}


${ }^{\mathrm{a}}$ Due to nonresponse, $\mathrm{n}=37$ for ethnicity and income among those who did not complete the study. Percentages reflect percent of valid responses.

${ }^{\mathrm{b}} \mathrm{GED}$ : General Educational Development.

${ }^{\mathrm{c}}$ PTSD: posttraumatic stress disorder.

\section{Outcomes}

\section{Use}

On average, participants listened to the health education podcasts for 103.2 (SD 29.5) minutes per week (see Figure 4), translating

Figure 4. Average minutes using podcast app by week. to an average of 4.9 (SD 0.9) completed podcast sessions each week (see Figure 5). For $83.3 \%$ (10/12) of the weeks, at least $70 \%$ of participants completed at least $70 \%$ of their total prescribed use (ie, $42 \mathrm{~min} /$ week; see Figure 6).

200

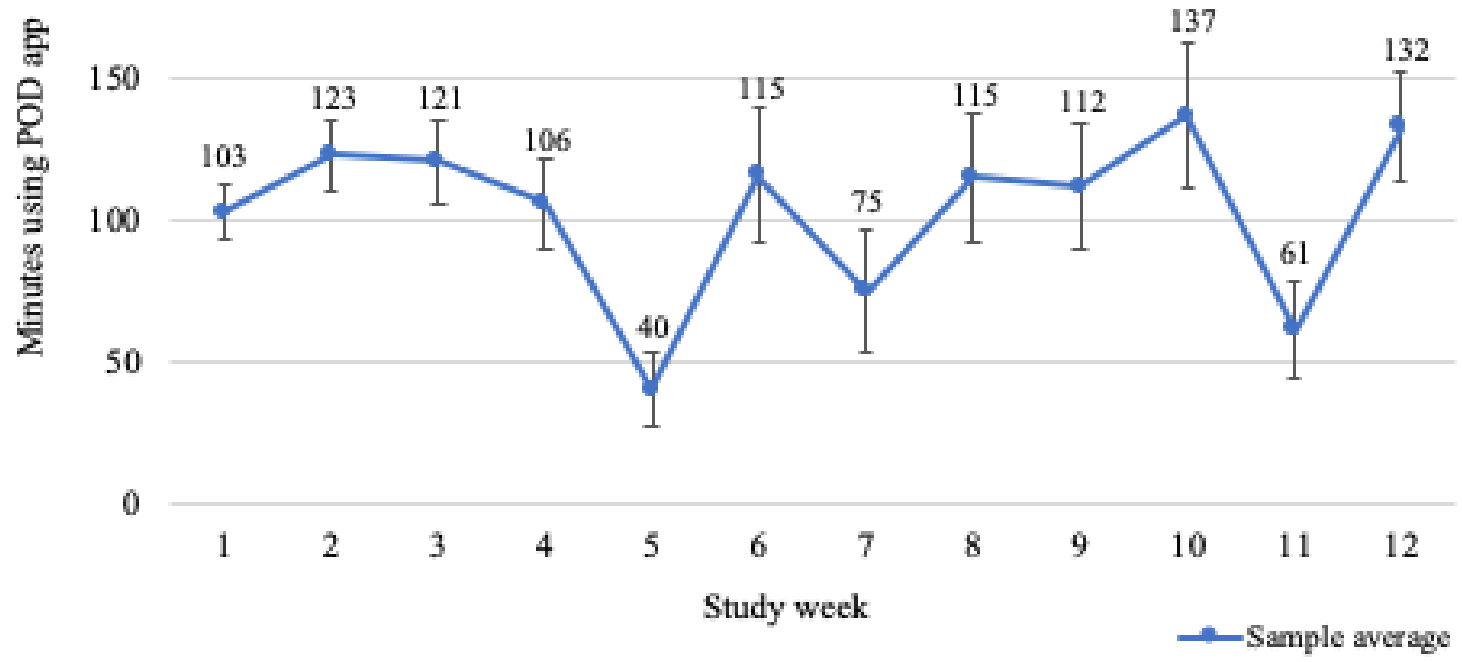

Figure 5. Average podcast sessions completed by week.

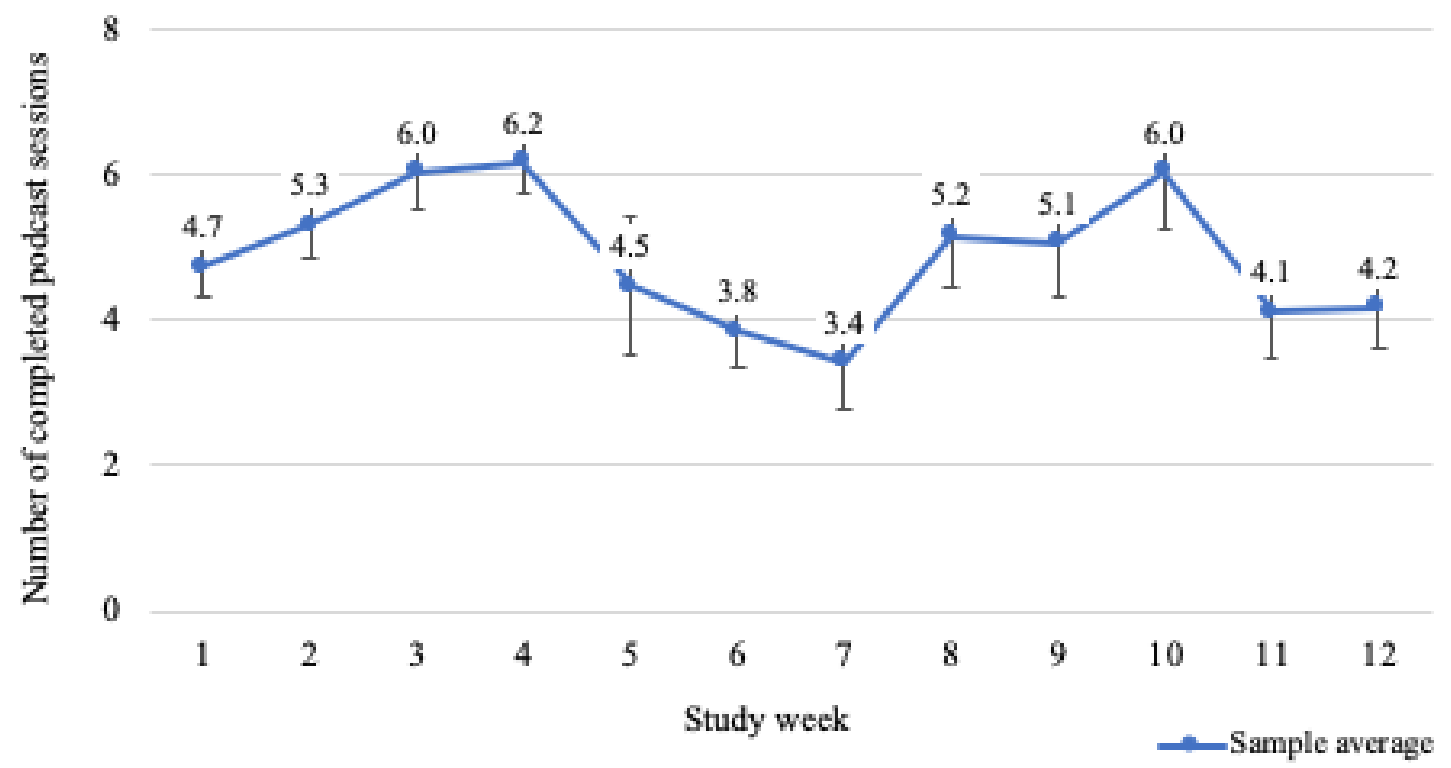


Figure 6. Percent adherence to prescribed podcast app use by week.

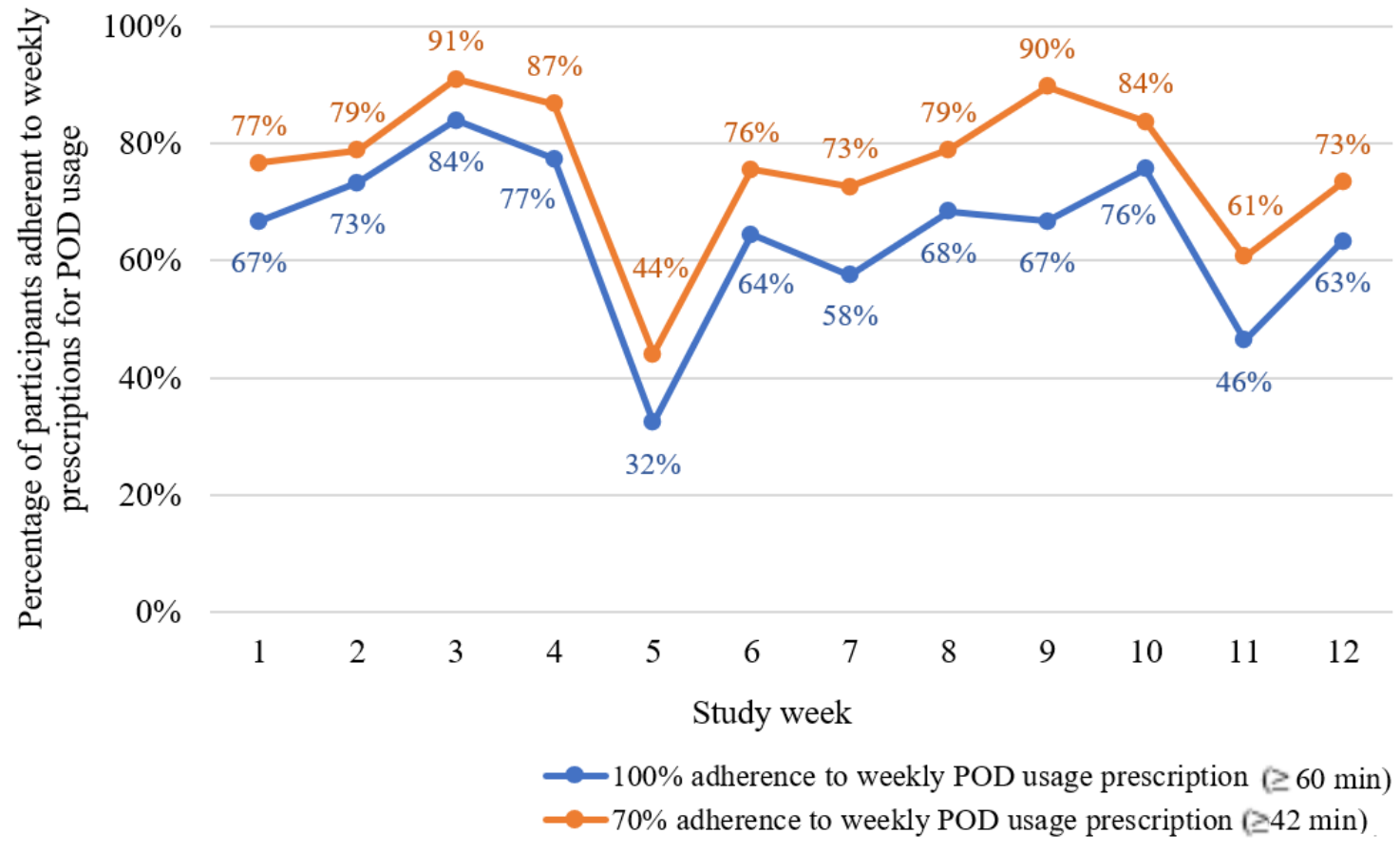

\section{Satisfaction}

Because we were unable to obtain satisfaction survey data from those who discontinued the study, satisfaction survey data were available only for study completers $(n=39)$. Almost half of participants reported that, overall, they enjoyed the health education podcasts $(n=19,48.7 \%)$ and that they were satisfied with the intervention $(n=17,43.6 \%)$. Approximately half indicated that they learned something about their MPN or cancer in general from the podcasts $(n=21,53.8 \%)$, and $51.3 \%(n=20)$ reported that they made changes to their normal daily activities because of something that they learned in the podcasts. More than half of participants $(n=22,56.4 \%)$ indicated that they would recommend the 12-week podcast prescription to other patients with MPN.

Over half of the 39 participants $(n=20,51.3 \%)$ experienced some form of logistical limitation during the intervention. Specifically, $4(10.3 \%)$ participants reported that they had difficulty hearing or viewing the podcasts (eg, too small on the screen), and $1(2.6 \%)$ reported bad or slow internet connection. However, most frequently, participants indicated that they had "other" problems that were not available as survey response options $(n=15,38.5 \%)$. Of the 15 participants who provided open-ended responses describing their "other" difficulties, the most common were general problems with app functionality $(\mathrm{n}=7,46.7 \%)$, problems accessing specific podcasts $(\mathrm{n}=5$, $33.3 \%$ ), or problems accessing any app content (ie, could not engage with any podcast; $n=3,20.0 \%$ ). When asked if there was anything else they would like to share with us, the majority $(21 / 34,62 \%)$ that responded to this question made recommendations for changes to the podcast content, either to make it more specific to MPN or because they did not enjoy certain podcasts.

\section{Changes in Health and Cancer-Related Symptoms}

As shown in Table 2, using the health education podcasts was not associated with significant changes in global health, specific cancer-related symptoms, or MPN-SAF TSS. 
Table 2. Changes in health and cancer-related symptoms during and after the health education podcast intervention $(n=37)$.

\begin{tabular}{|c|c|c|c|c|c|c|}
\hline Outcome & Baseline, mean (SD) & Week 6, mean (SD) & Week 12, mean (SD) & $F$ test $(d f)^{\mathrm{a}}$ & $P$ value $^{\mathrm{a}}$ & Partial $\eta^{2}$ \\
\hline Global health & & & & $0.29(1,36)$ & .88 & 0.033 \\
\hline Physical health & $33.24(7.22)$ & $33.08(7.50)$ & $33.62(7.75)$ & $0.46(1,36)$ & .50 & 0.012 \\
\hline Mental health & $40.01(7.65)$ & $39.76(8.29)$ & $39.63(8.53)$ & $0.27(1,36)$ & .61 & 0.007 \\
\hline Cancer-related symptoms & & & & $0.53(1,36)$ & .83 & 0.127 \\
\hline Anxiety & $51.25(8.00)$ & $52.99(7.51)$ & $52.52(7.29)$ & $1.54(1,36)$ & .22 & 0.041 \\
\hline Depression & $49.46(7.54)$ & $48.81(6.83)$ & $49.71(7.11)$ & $0.04(1,36)$ & .84 & 0.001 \\
\hline Pain intensity & $41.77(7.44)$ & $41.56(8.13)$ & $42.26(8.42)$ & $0.23(1,36)$ & .64 & 0.006 \\
\hline Sleep disturbance & $53.2(8.62)$ & $53.43(8.55)$ & $53.05(8.56)$ & $0.02(1,36)$ & .90 & $<0.001$ \\
\hline MPN-SAF TSS ${ }^{b}$ & $24.97(15.44)$ & $22.58(15.63)$ & $22.71(16.00)$ & $1.99(1,36)$ & .17 & 0.051 \\
\hline
\end{tabular}

${ }^{\text {a }} F$ test and $P$ values assume symptom change to be a linear trend over time. Examination of change as a quadratic function produced similar results. For 2 participants, complete data were unavailable; they were excluded from the multivariate analyses.

bMPN-SAF TSS: Myeloproliferative Neoplasm Symptom Assessment Form Total Symptom Score.

\section{Discussion}

\section{Principal Results}

The purpose of this study was to beta test a health education podcast control group delivered via a smartphone app to inform the development of a comparator that could be used in future app-based meditation intervention studies. Feasibility benchmarks were met for demand (ie, for 10 of the 12 weeks at least $70 \%$ of participants listened to at least $42 \mathrm{~min} /$ week of podcasts); although, the attrition should be noted as an important qualifier when considering engagement more broadly. Acceptability benchmarks were not met, as less than half of participants enjoyed the podcasts and were satisfied with the intervention. As expected, there were no changes in global health, cancer-related symptoms, or total symptom burden (ie, MPN-SAF TSS) over the 12 weeks.

\section{Comparison With Prior Work}

Use benchmarks were set at $\geq 70 \%$ of participants listening to $\geq 70 \%$ (ie, $42 \mathrm{~min} /$ week) of the prescribed total weekly podcasts. In nearly all weeks (ie, 10 out of the 12 weeks) this benchmark was met. This is encouraging as a control group in which participants adhere to the study prescriptions allows researchers to control for nonintervention treatment effects such as time and attention [4]. Furthermore, participants averaged 103 $\mathrm{min} /$ week of podcast listening or viewing. Other studies that have tested mobile-app control groups have not reported weekly participation data $[13,26]$. In our research studies in which we used a commercially available meditation app in college students for 8 weeks [15] and to patients with MPN cancer for 4 weeks [16], average weekly participation in meditation on the app was $\sim 38 \mathrm{~min} /$ week and $\sim 71 \mathrm{~min} /$ week, respectively. Our findings are promising because the use of the podcast control app was comparable to the use levels in our intervention studies, supporting its feasibility for a control group with the same time and attention as a consumer-based mobile app meditation intervention.

Satisfaction benchmarks were not met, indicating that participants' overall satisfaction with the app was lacking. Less than half of participants indicated that they enjoyed the health education podcasts and less than half indicated that they were satisfied with the intervention. This is likely due to the podcast topics and technical issues and difficulties that came up during the intervention related to the functionality and usability of the app. The majority of participants that responded to an open-ended question to provide additional feedback about the study reported that they thought the app content should be modified to include more MPN-specific education or higher quality podcasts. The podcasts selected for the control app were intended to provide more generic cancer-related health education and not MPN-specific education. A better understanding of the potential users' content preferences with a more user-centered approach is necessary for future iterations of the control app, especially because the app was designed to be able to change health-education podcasts per target population being studied. A user-centered approach when developing products or software may help the user feel more at ease and make engaging with the content more intuitive, potentially improving adherence and enjoyment [27].

Over half of participants reported experiencing trouble accessing podcasts or content, or general problems with the functionality of the app. The app was not developed to be of commercial quality but was rather developed to be a "shell" of a design to be improved upon in subsequent developments after beta testing. Therefore, it is not surprising that such technical difficulties related to app functionality and accessibility were experienced. Specifically, there was a decrease in participation during week five, coinciding with participants reporting technical difficulties to the research staff. It is well known that user experience is a critical component to the success of mHealth apps and that apps must appeal to the motivations of the user [28]. For example, the unified theory of acceptance and use of technology (UTAUT) suggests that users' expectations of how an app will perform and how much effort it takes to use the app will influence their intentions and behaviors [29-31]. Future iterations of this app will use the current findings and a model-driven approach (eg, the UTAUT) to inform the 
development of the next version of the app to be used as a comparator in a randomized control trial.

Importantly, there were no significant changes in health or cancer-related symptoms from baseline to postintervention. This is despite more than half of the participants reporting that they made changes to their normal daily activities because of something they learned from the podcasts. This is encouraging and indicates that this control group design is an appropriate time- and attention-matched condition that is not associated with any meaningful change in study outcomes. Education-based control groups have been used successfully as comparators in a range of smartphone-based interventions across different populations, typically without having significant effects on psychological or physical outcomes $[13,16,26]$. This indicates that an education-based control group could be appropriate for use in efficacy trials without producing changes in primary outcomes that are physical or psychological in nature. Future iterations of the app will be evaluated as a comparator in studies with other populations.

\section{Limitations}

This study is not without its limitations. First, attrition during the study was high, such that only $51 \%(41 / 80)$ of participants completed the full 12-week intervention. Given that the podcast app use (minutes listened per week) was high even when including use of participants who did not complete the study, future research should collect more nuanced data on participant satisfaction to improve podcast app user experiences and reduce attrition rates. For example, the lack of a postintervention interview did not allow for deeper qualitative analyses into what participants liked and did not like related to the app. This qualitative data could have been a useful addition for gathering deeper insights into user satisfaction and informing future development of the app. Second, the sample was predominantly White, non-Hispanic, and female. This is not representative of the general population of patients with MPN and, more importantly for the purpose of this beta test, does not capture feedback that reflects the experiences of different genders, races, and ethnicities. Future feasibility research should aim to include more diverse samples to gather more representative feedback.
Third, there was no comparative group, and this must be considered when analyzing the results. Fourth, offering a US \$25 digital gift card for completion of all questionnaires could contribute to higher engagement rates. Researchers may need to account for an impact on their participant engagement if they do not provide similar incentivization. Finally, the use of cancer-specific educational content would limit the app as currently developed to use in cancer studies only. However, the content of the app can easily be adjusted to fit the needs of different populations while maintaining the integrity and functionality of the app to match the Calm meditation app.

\section{Future Research}

Although this app was originally designed to be a comparative control app for app-based mindfulness meditation interventions involving Calm, the app is not reliant on the use of Calm and may be used as a control app in future app-based interventions. Currently, this app is not available to other researchers because it was only developed as a template to then create an improved comparator app for future mindfulness meditation app-based interventions based on the data collected. Once the app can be determined feasible, future interventions will be developed to assess app-based mindfulness meditation interventions as compared to the control app to assess many aspects of health and well-being across various populations.

\section{Conclusion}

In summary, a 12-week mobile app health education podcast met the demand benchmark but not the acceptability benchmark for feasibility in a sample of patients with hematological cancer. Using the mobile app health education podcast was not associated with significant changes in cancer-related symptoms. Participants reported dissatisfaction with content and technical or functionality difficulties, which will be addressed in the future development of the health education podcast app. Based on findings from this study, a mobile app health education podcast may be a feasible option as a time- and attention-matched comparator condition for efficacy trials with more extensive formative research for the content of the podcasts and its acceptability by the specific population.

\section{Acknowledgments}

This study was funded with philanthropic funds.

\section{Conflicts of Interest}

JH and LL both report being members of the Scientific Advisory Board for Calm and serve in paid consulting roles. Neither earn additional financial compensation from the sale of the app. The remaining authors report no conflicts of interest.

\section{References}

1. Mobile fact sheet. Pew Research Center. 2019. URL: https://www.pewresearch.org/internet/fact-sheet/mobile/ [accessed 2019-12-31]

2. mHealth: New horizons of health through mobile technology. World Health Organization. 2011. URL: https://www.who.int/ goe/publications/goe mhealth web.pdf? [accessed 2018-12-31]

3. Robbins R, Krebs P, Jagannathan R, Jean-Louis G, Duncan DT. Health app use among US mobile phone users: analysis of trends by chronic disease status. JMIR Mhealth Uhealth 2017 Dec 19;5(12):e197 [FREE Full text] [doi:

10.2196/mhealth.7832] [Medline: 29258981] 
4. Dorsey ER, Yvonne Chan YF, McConnell MV, Shaw SY, Trister AD, Friend SH. The use of smartphones for health research. Acad Med 2017 Feb;92(2):157-160. [doi: 10.1097/ACM.0000000000001205] [Medline: 27119325]

5. Kinser PA, Robins JL. Control group design: enhancing rigor in research of mind-body therapies for depression. Evid Based Complement Alternat Med 2013;2013:140467. [doi: 10.1155/2013/140467] [Medline: 23662111]

6. Hart T, Fann JR, Novack TA. The dilemma of the control condition in experience-based cognitive and behavioural treatment research. Neuropsychol Rehabil 2008 Jan;18(1):1-21. [doi: 10.1080/09602010601082359] [Medline: 17852761]

7. Duraimani SL. A cross-sectional and longitudinal study of the effects of a mindfulness meditation mobile application platform on reducing stress and anxiety. Int J Yoga 2019;12(3):226-232 [FREE Full text] [doi: 10.4103/ijoy.IJOY 56 18] [Medline: 31543631]

8. Flett JAM, Hayne H, Riordan BC, Thompson LM, Conner TS. Mobile mindfulness meditation: a randomised controlled trial of the effect of two popular apps on mental health. Mindfulness 2018 Oct 31;10(5):863-876. [doi:

10.1007/s12671-018-1050-9]

9. Romeo A, Edney S, Plotnikoff R, Curtis R, Ryan J, Sanders I, et al. Can smartphone apps increase physical activity? systematic review and meta-analysis. J Med Internet Res 2019 Mar 19;21(3):e12053 [FREE Full text] [doi: 10.2196/12053] [Medline: $\underline{30888321]}$

10. Freedland KE, King AC, Ambrosius WT, Mayo-Wilson E, Mohr DC, Czajkowski SM, National Institutes of Health Office of Behavioral and Social Sciences Research Expert Panel on Comparator Selection in Behavioral and Social Science Clinical Trials. The selection of comparators for randomized controlled trials of health-related behavioral interventions: recommendations of an NIH expert panel. J Clin Epidemiol 2019 Jun;110:74-81 [FREE Full text] [doi: 10.1016/j.jclinepi.2019.02.011] [Medline: $\underline{30826377]}$

11. Lunde P, Nilsson BB, Bergland A, Kværner KJ, Bye A. The effectiveness of smartphone apps for lifestyle improvement in noncommunicable diseases: systematic review and meta-analyses. J Med Internet Res 2018 May 04;20(5):e162 [FREE Full text] [doi: 10.2196/jmir.9751] [Medline: 29728346]

12. Bostock S, Crosswell AD, Prather AA, Steptoe A. Mindfulness on-the-go: effects of a mindfulness meditation app on work stress and well-being. J Occup Health Psychol 2019 Feb;24(1):127-138 [FREE Full text] [doi: 10.1037/ocp0000118] [Medline: 29723001]

13. Champion L, Economides M, Chandler C. The efficacy of a brief app-based mindfulness intervention on psychosocial outcomes in healthy adults: a pilot randomised controlled trial. PLoS One 2018;13(12):e0209482. [doi:

10.1371/journal.pone.0209482] [Medline: 30596696]

14. Economides M, Martman J, Bell MJ, Sanderson B. Improvements in stress, affect, and irritability following brief use of a mindfulness-based smartphone app: a randomized controlled trial. Mindfulness (N Y) 2018;9(5):1584-1593 [FREE Full text] [doi: 10.1007/s12671-018-0905-4] [Medline: $\underline{\text { 30294390] }}$

15. Carissoli C, Villani D, Riva G. Does a meditation protocol supported by a mobile application help people reduce stress? Suggestions from a controlled pragmatic trial. Cyberpsychol Behav Soc Netw 2015 Jan;18(1):46-53. [doi: 10.1089/cyber.2014.0062] [Medline: 25584730]

16. Huberty J, Green J, Glissmann C, Larkey L, Puzia M, Lee C. Efficacy of the mindfulness meditation mobile app "Calm" to reduce stress among college students: randomized controlled trial. JMIR Mhealth Uhealth 2019 Jun 25;7(6): e14273 [FREE Full text] [doi: 10.2196/14273] [Medline: 31237569]

17. Huberty J, Eckert R, Larkey L, Kurka J, Rodríguez De Jesús SA, Yoo W, et al. Smartphone-based meditation for myeloproliferative neoplasm patients: feasibility study to inform future trials. JMIR Form Res 2019 Apr 29;3(2):e12662 [FREE Full text] [doi: 10.2196/12662] [Medline: $\underline{31033443}$ ]

18. Adams ZW, Sieverdes JC, Brunner-Jackson B, Mueller M, Chandler J, Diaz V, et al. Meditation smartphone application effects on prehypertensive adults' blood pressure: dose-response feasibility trial. Health Psychol 2018 Sep;37(9):850-860 [FREE Full text] [doi: 10.1037/hea0000584] [Medline: $\underline{\text { 30010353] }}$

19. Bowen DJ, Kreuter M, Spring B, Cofta-Woerpel L, Linnan L, Weiner D, et al. How we design feasibility studies. Am J Prev Med 2009 May;36(5):452-457 [FREE Full text] [doi: 10.1016/j.amepre.2009.02.002] [Medline: 19362699]

20. Huberty J, Eckert R, Gowin K, Mitchell J, Dueck AC, Ginos BF, et al. Feasibility study of online yoga for symptom management in patients with myeloproliferative neoplasms. Haematologica 2017 Oct;102(10):e384-e388 [FREE Full text] [doi: 10.3324/haematol.2017.168583] [Medline: 28596279]

21. Cessna JM, Jim HSL, Sutton SK, Asvat Y, Small BJ, Salsman JM, et al. Evaluation of the psychometric properties of the PROMIS Cancer Fatigue Short Form with cancer patients. J Psychosom Res 2016 Feb;81:9-13 [FREE Full text] [doi: 10.1016/j.jpsychores.2015.12.002] [Medline: 26800633]

22. Flynn KE, Lin L, Cyranowski JM, Reeve BB, Reese JB, Jeffery DD, et al. Development of the NIH PROMIS $®$ Sexual Function and Satisfaction measures in patients with cancer. J Sex Med 2013 Feb;10 Suppl 1:43-52 [FREE Full text] [doi: 10.1111/j.1743-6109.2012.02995.x] [Medline: 23387911]

23. Hays RD, Bjorner JB, Revicki DA, Spritzer KL, Cella D. Development of physical and mental health summary scores from the patient-reported outcomes measurement information system (PROMIS) global items. Qual Life Res 2009 Sep;18(7):873-880 [FREE Full text] [doi: 10.1007/s11136-009-9496-9] [Medline: 19543809] 
24. Quach CW, Langer MM, Chen RC, Thissen D, Usinger DS, Emerson MA, et al. Reliability and validity of PROMIS measures administered by telephone interview in a longitudinal localized prostate cancer study. Qual Life Res 2016 Nov;25(11):2811-2823 [FREE Full text] [doi: 10.1007/s11136-016-1325-3] [Medline: 27240448]

25. Scherber R, Dueck AC, Johansson P, Barbui T, Barosi G, Vannucchi AM, et al. The Myeloproliferative Neoplasm Symptom Assessment Form (MPN-SAF): international prospective validation and reliability trial in 402 patients. Blood 2011 Jul 14;118(2):401-408. [doi: 10.1182/blood-2011-01-328955] [Medline: 21536863]

26. Bush NE, Smolenski DJ, Denneson LM, Williams HB, Thomas EK, Dobscha SK. A Virtual Hope Box: randomized controlled trial of a smartphone app for emotional regulation and coping with distress. Psychiatr Serv 2017 Apr 01;68(4):330-336. [doi: 10.1176/appi.ps.201600283] [Medline: 27842473]

27. Goodwin K. Designing for the Digital Age: How to Create Human-Centered Products and Services. Hoboken, New Jersey: John Wiley \& Sons; 2011.

28. Liew MS, Zhang J, See J, Ong YL. Usability challenges for health and wellness mobile apps: mixed-methods study among mHealth experts and consumers. JMIR Mhealth Uhealth 2019 Jan 30;7(1):e12160 [FREE Full text] [doi: 10.2196/12160] [Medline: $\underline{30698528}$ ]

29. Stawarz K, Preist C, Tallon D, Wiles N, Coyle D. User experience of cognitive behavioral therapy apps for depression: an analysis of app functionality and user reviews. J Med Internet Res 2018 Jun 06;20(6):e10120 [FREE Full text] [doi: 10.2196/10120] [Medline: 29875087]

30. Di Sorbo AP, Alexandru C, Shimagaki J, Visaggio C, Canfora G, Gall H. What would users change in my app? Summarizing app reviews for recommending software changes. In: Proceedings of the 2016 24th ACM SIGSOFT International Symposium on Foundations of Software Engineering. 2016 Presented at: 24th ACM SIGSOFT International Symposium on Foundations of Software Engineering; 2016; Seattle, Washington p. 499-510. [doi: 10.1145/2950290.2950299]

31. Frie K, Hartmann-Boyce J, Jebb S, Albury C, Nourse R, Aveyard P. Insights from Google Play Store user reviews for the development of weight loss apps: mixed-method analysis. JMIR Mhealth Uhealth 2017 Dec 22;5(12):e203 [FREE Full text] [doi: 10.2196/mhealth.8791] [Medline: 29273575]
Abbreviations
mHealth: mobile health
MPN: myeloproliferative neoplasm
MPN-SAF TSS: Myeloproliferative Neoplasm Symptom Assessment Form Total Symptom Score
NIH: National Institutes of Health
PROMIS: Patient-Reported Outcomes Measurement Information System
UTAUT: unified theory of acceptance and use of technology

Edited by G Eysenbach; submitted 14.04.20; peer-reviewed by M Economides, K Frie; comments to author $11.05 .20 ;$ revised version
received $27.05 .20 ;$ accepted 14.06.20; published 21.07 .20
Please cite as:
Huberty J, Eckert R, Puzia M, Laird B, Larkey L, Mesa R
A Novel Educational Control Group Mobile App for Meditation Interventions: Single-Group Feasibility Trial
JMIR Form Res 2020;4(7):e19364
URL: $\underline{\text { http://formative.jmir.org/2020/7/e19364/ }}$
doi: $\underline{10.2196 / 19364}$
PMID: $\underline{32706719}$

(CJennifer Huberty, Ryan Eckert, Megan Puzia, Breanne Laird, Linda Larkey, Ruben Mesa. Originally published in JMIR Formative Research (http://formative.jmir.org), 21.07.2020. This is an open-access article distributed under the terms of the Creative Commons Attribution License (https://creativecommons.org/licenses/by/4.0/), which permits unrestricted use, distribution, and reproduction in any medium, provided the original work, first published in JMIR Formative Research, is properly cited. The complete bibliographic information, a link to the original publication on http://formative.jmir.org, as well as this copyright and license information must be included. 